\title{
Interações e dinâmicas espaciais nos sertões do Piauí: Área Urbana Funcional (FUA) e aspectos de Policentrismo a partir de uma Cidade de Comando Regional Piauiense
}

Interactions et dynamiques spatiales dans les sertões de Piauí: Espace urbain fonctionnel (EUF) et aspects du polycentrisme d'une ville de Commandement Régional Piauiense Interacciones y dinámicas espaciales em los sertones de Piauí: Área Urbana Funcional (FUA) y aspectos de Policentrismo apartir de una Ciudad de Comando Regional de Piauí

Interactions and spatial dynamics in the Piauí outbacks: Functional Urban Area (FUA) and Policentrism aspects since a Regional Command City from Piauí.

\section{Juscelino Gomes Lima}

\section{(2) OpenEdition}

\section{Journals}

Edição electrónica

URL: http://journals.openedition.org/espacoeconomia/5729

DOI: $10.4000 /$ espacoeconomia.5729

ISSN: 2317-7837

Editora

Núcleo de Pesquisa Espaço \& Economia

Refêrencia eletrónica

Juscelino Gomes Lima, «Interações e dinâmicas espaciais nos sertões do Piauí: Área Urbana

Funcional (FUA) e aspectos de Policentrismo a partir de uma Cidade de Comando Regional Piauiense », Espaço e Economia [Online], 14 | 2019, posto online no dia 11 agosto 2019, consultado o 04 setembro 2019. URL : http://journals.openedition.org/espacoeconomia/5729; DOI : 10.4000/ espacoeconomia.5729

Este documento foi criado de forma automática no dia 4 Setembro 2019.

(c) NUPEE 


\section{Interações e dinâmicas espaciais nos} sertões do Piauí: Área Urbana Funcional (FUA) e aspectos de Policentrismo a partir de uma Cidade de Comando Regional Piauiense

Interactions et dynamiques spatiales dans les sertões de Piauí: Espace urbain fonctionnel (EUF) et aspects du polycentrisme d'une ville de Commandement Régional Piauiense

Interacciones y dinámicas espaciales em los sertones de Piauí: Área Urbana Funcional (FUA) y aspectos de Policentrismo apartir de una Ciudad de Comando Regional de Piauí Interactions and spatial dynamics in the Piauí outbacks: Functional Urban Area (FUA) and Policentrism aspects since a Regional Command City from Piauí.

Juscelino Gomes Lima

\section{Introdução:}

Situada nos sertões leste do território piauiense a cidade de Picos tem em seu quadro regional de localização, sob sua influência, cinquenta e cinco municípios. $O$ grande raio de polarização e comando em sua região é justificado pela presença e concentração de um variado conjunto de comércios e redes de lojas, bem como de serviços, sejam eles, públicos e ou privados, voltados por um lado, para os setores de saúde e educação e 
também, por outro, para o fomento da produção dos Arranjos Produtivos Locais (APL's) do caju e apícola.

2 A centralidade destes equipamentos/serviços diariamente instiga o movimento de grandes fluxos populacionais rumo à Picos, buscando negociar, consumir e resolver uma série de demandas pessoais. Nesse contexto, é observada uma intrínseca relação entre este conjunto de cidades com sua região, resultante das dinâmicas territoriais, fortemente acumuladas nas últimas duas décadas. Tais fatos, expõe região de Picos à lógica de conexão, do lugar-mundo.

3 A qualificação de Picos, enquanto uma importante Área Urbana Funcional (FUA), ganha escopo de importância, quando se faz conjugada com os estudos do policentrismo ou policentricidade, que de modo bem direto, diz respeito à existência de um conjunto de "centros urbanos, com diferentes funções econômicas e de gestão, com distintas capacidades e condições de centralidades urbana, que se inter-relacionam, num dado espaço regional" (SILVEIRA et al, 2017, p. 184).

4 Picos, no Piauí, é a representação destes fatos: uma cidade que em seu contexto regional, se apresenta como uma importante FUA, interagindo com um amplo número de municípios e dando condições para um dinamismo espacial, capaz de consagrar um novo sentido de ser e ou estar, nos sertões. Tal consagração ganha respaldo, quando é lembrado que na perspectiva imagética, dos discursos e planejamentos estatais de gabinete, os sertões sempre foi sinônimo de atraso e pouca vanguarda, comparativamente a outros recortes regionais do país.

5 Em continuidade a este pensamento, o presente texto, analisa Picos enquanto uma Área Urbana Funcional (FUA), bem como, a constituição de um forte policentrismo, cujos aspectos tomados são os da morfologia e as relações entre àreas urbanas, decorrentes das diferentes interações e dinâmicas espaciais, em seu território regional.

Dois caminhos metodológicos norteiam a construção da pesquisa: o primeiro, de base teórica, entre diferentes pensadores, na literatura urbano e regional. 0 segundo, de natureza quantitativa, por meio de diferentes dados, de caráter primário e secundários. Nestes últimos, há destaque para os estudos do IBGE: Gestão do Território - Fluxos e Redes (2014) e REGIC (2007).

7 As múltiplas interações espaciais, representadas pelos diversificados fluxos, têm contribuído para fortes dinâmicas nos sertões do Piauí. A capacidade de comando regional de Picos tem reafirmado sua condição de uma importante Área Urbana Funcional (FUA), em seu contexto regional. Os aspectos policêntricos apontados, são animados e resultam dessa premissa.

80 artigo é constituído de quatro seções: (i): Áreas Urbanas Funcionais (FUA's), Policentrismo Funcional e Cidades de Comando Regional: elementos teóricos, referências empíricas; (ii) Picos/PI: da sua localização à sua caracterização regional; (iii) Região sertaneja do Piauí em interatividade: Picos/PI em destaque e (iv) Considerações finais. Finaliza a composição, a listagem das referências bibliográficas.

9 Áreas Urbanas Funcionais (FUA's), Policentrismo Funcional e Cidades de Comando Regional: elementos teóricos, referências empíricas

10 Em princípio, é necessário lembrar que, o entendimento acerca das FUA's, passa pela compreensão conceitual sobre regiões funcionais, que diga-se de passagem, é multiforme, ou seja, há uma gama variada de sentidos teóricos/conceituais que a envolve. Tal 
condição é dada pela variedade dos aspectos relacionais que esta categoria analítica aborda: relações urbano-rurais; rurais-urbanas e ou ainda ambas, de forma paralela.

De forma direta, Ferrão (2012, p. 10) nos diz que as regiões funcionais são caracterizadas "sempre por possuir interações relevantes e por deter, efetiva ou potencialmente, uma estrutura bem definida e hierarquizada, ainda que nem sempre facilmente delimitável" Interações, sinônimo de ligações/conectividades, aparecem como ideias chave destas regiões. Pensando assim, tal condição, pressupõe que as mesmas mantenham diálogos e laços de dependência, à própria região ou com outras regiões delas próximas (ou não necessariamente!), a partir de suas funcionalidades (leia-se serventias, funções e ou usos). Contudo, não se estar a falar das regiões, em sentido per si, sem conteúdo, mas dotadas de recortes territoriais urbanos, com respectivas funcionalidades.

13 Nesse contexto, a discussão de regiões funcionais, tem uso renovado no planejamento regional, a partir da União Europeia e OCDE. O reconhecimento e importância de tais regiões, para estes organismos, se dão em dois níveis: o analítico (construção de diagnósticos e cenários prospectivos) e o de intervenção (visão estratégica de desenvolvimento e de políticas públicas).

14 Nesse contexto de visão, a partir dos órgãos citados, a definição de regiões funcionais perpassa três perspectivas conceituais: Travel-To-Work Area (espaços para onde se viaja à trabalho); Áreas Urbanas Funcionais (na Europa, é tomado por base, a funcionalidade, a partir dos fluxos migratórios, entre centros urbanos de influência que apresentem populações, entre 15 a 50 mil habitantes) e Região Funcional (toma como referência de critérios, os movimentos pendulares e mercados de trabalho).

Há algo em comum, entre as perspectivas apresentadas: movimentos, fluxos. Estes elementos ajudam a conectar e dar sinergia, entre as cidades e as regiões, qualificadas como funcionais. Partindo da realidade europeia, a mobilidade dos fluxos se dá entre diferentes motivos, sobretudo, os que "estão ligados aos mercados de trabalho e educação, bem como à formação familiar, enquanto os motivos para se deslocar dentro das FUA's estão mais ligados a atributos qualitativos" (ANTIKAINEN, 2005, p. 447). é a alta frequência de interações, a partir das diferentes populações, que moram em outras cidades, do recorte regional, para com os diferentes segmentos econômicos. Destes, há destaque, para os ramos de comércios, de bens e serviços, acompanhados pelos deslocamentos para atividades de trabalho, processadas no interior da região.

17 Com isso, o elo de relações e de ligações, entre as cidades e destas com suas regiões, se fazem respaldadas pelo agrupamento de atividades, bem como, de uma infraestrutura regional de transportes, capazes de facilitar o amplo movimento e mobilidade de pessoas, produtos e insumos, dentro de suas fronteiras (KARLSON; OLSSON, 2006).

18 No contexto da realidade brasileira, mas particularmente, sobre as cidades localizadas fora dos quadros metropolitanos, vale lembrar os motivos que desde os anos de 1980, vem animando a promoção de novos quadros urbanos regionais, referendados pelas mobilidades populacionais que "vem circulando em torno da desconcentração industrial/ populacional, reestruturação produtiva, redução nos volumes dos fluxos migratórios, baixa atratividade das metrópoles nacionais, mudança no mundo do trabalho" (OLIVEIRA, 2006, p. 16).

19 Paralelo às FUA's, também advindo da realidade urbano e regional da Europa, sobretudo, com fins de estudos e planejamento/gestão dos territórios regionais, emerge o ideal de 
policentrismo funcional, a partir do Observatório Europeu de Ordenamento do Território (ESPON).

Sua perspectiva, está atrelada à sobreposição da visão de cidade monocêntrica, oportunidade em que as novas formas espaciais urbanas contemporâneas, dão sentido de compreensão para visão da cidade policêntrica. Esta tipologia, apresenta vários centros e a partir destes, diferentes usos e funcionalidades, particularmente, por destacar e correlacionar dois aspetos complementares à esta compreensão tradicional de policentrismo: a morfologia do espaço (número e hierarquia de cidades) e as relações funcionais entre áreas urbanas (redes, fluxos, cooperação) (ESPON, 2005). europeu é "definido com base na especialização funcional das áreas urbanas e não com base no seu tamanho ou dimensão, sendo referenciado como um modelo alternativo ao da concentração metropolitana em torno de grandes cidades" (NUNES et al, 2012, p. 28).

Depreende-se de um lado que, quando se fala em morfologia do espaço, reporta-se às variáveis que dizem respeito a hierarquia urbana, quantitativo de cidades, bem como sua distribuição. No tocante as relações funcionais, cabe lembrar das capacidades de fluxos, sejam eles materiais e ou imateriais, bem como, o sentido de cooperação, entre as unidades urbanas regionalmente envolvidas.

Por outro lado, ao mencionar o aspecto da morfologia, é necessário lembrar da possível capacidade de contiguidade, de áreas urbanas construídas e envolvidas na dinâmica de relações regionais, a partir da principal FUA. Na Europa, tal condição, é conhecida como morfological urban areas - MUA's ou áreas urbanas morfológicas.

É formado entre ambas, "cinturões pendulares", cuja principal marca, são os movimentos e mobilidades de pessoas, dos núcleos urbanos vizinhos, rumo às MUA's, com destino à postos/atividades de trabalho. Nesse contexto, estudos da ESPON (2011), expõe a definição da forma, como se apresentam a estrutura e os limites de abrangência, dos contornos espaciais de uma FUA. É reconhecido assim, as principais dimensões que constituem aquelas cidades: a morfológica e a funcional.

Concernentemente à realidade urbana no Brasil, ainda que em muitos pontos e características, destoem da realidade europeia, se faz reconhecível a constituição e complexificação das espacialidades urbanas, em diferentes quadros regionais, onde os "arranjos urbanos brasileiros têm se desenvolvido em diferentes contextos da metropolização contemporânea, que se caracterizam pela complexidade das relações intraurbanas e pelo dinamismo de suas atividades" (PESSOA, 2011, p. 315).

Nesse contexto, a cidade de Picos, no Piauí, ainda que localizada fora dos quadros metropolitanos, apresenta condições complexas, na organização de suas formas espaciais, bem como de relações com outras unidades por elas polarizadas. É destas condições que,

o Projeto ESPON, no contexto das discussões aqui em apontamento, baseado em Durh (2005), traz colaborações à compreensões, sobre a realidade urbano e regional em apreço.

A referida autora, considera importante em análises das formas em questão, três aspectos de policentralidades: Morfologia, Relações entre Áreas Urbanas e de Governança. A compreensão mais apurada e de forma representativa, é apresentada na figura 1, logo a seguir. 
Fig. 1: Aspectos de policentricidades a partir do Projeto ESPON.

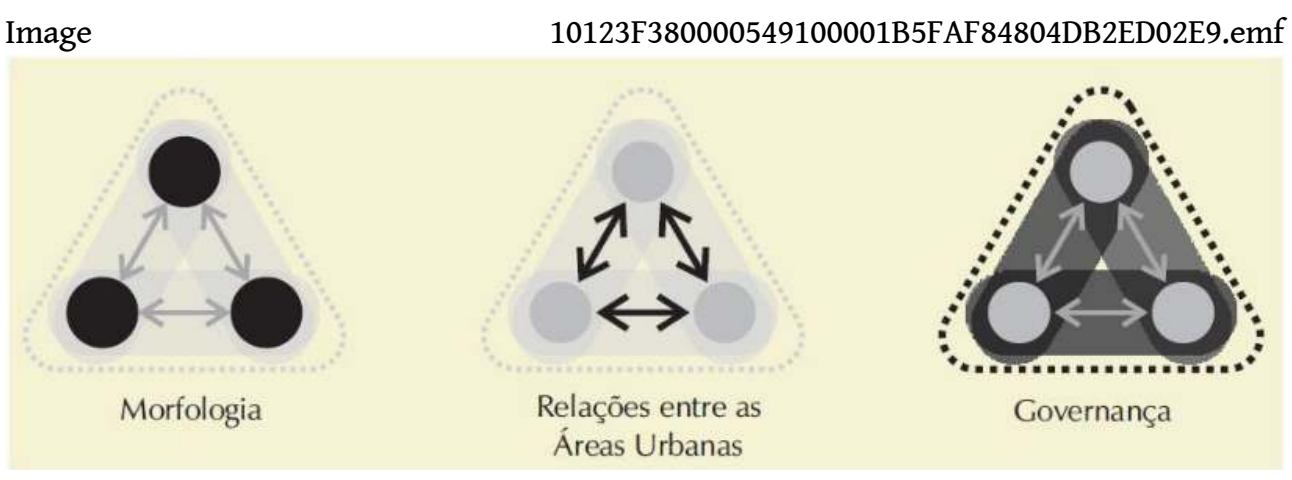

Fonte: Baseado em Dühr (2005). interurbanos. interligação.

Diferentemente dos dois primeiros aspectos, o que se refere à governança, não é alvo de analise empírica e discursiva no âmbito desta pesquisa. No tocante ao aspecto da morfologia, enquanto componente de análises desta pesquisa, o mesmo emerge como forte contribuinte, à compreensão das diferentes interações espaciais, no conjunto regional de Picos, cuja representação concreta se dá, pelos fluxos intrarregionais e

Justifica a constituição dos diferentes fluxos, processadas no território regional de Picos e cuja "desembocadura" se dá sobre esta cidade, o forte adensamento e localização das atividades comerciais e de serviços, influenciadores do reconhecimento dos padrões de policentrismo, revelador em parte, de sua capacidade funcional.

A outra parte e que vem ampliar a visualização da funcionalidade urbana de Picos, é a que diz respeito da relação entre as áreas urbanas. No contexto das cidades europeias, este aspecto é extremamente determinante, sobretudo, à luz dos interesses dos diferentes documentos que orientam o desenho de planejamento territorial, como foco nas realidades urbanas, na escala regional.

A constituição de relações, especialmente, a partir das cidades situadas fora dos quadros metropolitanos, considerando seus diferenciados recortes de localização e o volume de cidades por elas polarizadas, se faz à luz da correlação de forças, entre "sinergias e os fluxos da estrutura espacial (estrutural) e da cooperação voluntária (institucional) dentro de um sistema urbano" (DUHR, 2005, p. 235-236).

3 Essa correlação vai ao encontro com o ideal de funcionalidade policêntrica. As relações materializadas no âmbito do sistema policêntrico, movimentam mercadorias, pessoas, investimentos, interesses, perdas e ganhos de identidades territoriais. Tais características se ampliam à medida que, o raio de alcance de influência da cidade principal, se dá sobre outras, no recorte regional, de modo progressivo, a contar pelos seus "nós" de

Nesse encaminhamento, Green (2007, p. 2082) nos esclarece que a edificação estas relações, via de regra, se materializa em dois momentos: "em primeiro lugar, o espaço em questão deve conter mais de um nó e, segundo, os nós devem ser funcionalmente ligados entre si, de modo que se não houver conexões funcionais entre os nós, então, não se pode dizer que exista a policentricidade funcional".

Essa correlação no caso brasileiro, sejam elas, em quadros metropolitanos e ou fora dos mesmos, nas denominadas cidades médias, é situada no contexto dos dinâmicos 
“interesses econômicos, influenciados pelos meios de transportes e redes de comunicações, atuam com fluidez nos mais diversos territórios, se manifestando na apropriação do espaço intraurbano das cidades médias e das metrópoles" (ANDRADE, 2015, p. 67).

Temos então, palavras chave que explicam e justificam os fortes quadros de transformações na ordem urbana destas cidades, sua capacidade de polarização, em específicos recortes regionais: nós, fluxos, sinergias, ligações.

Dada a realidade de Picos, múltiplos são os caminhos, que organizam as relações e as capacidade de integração regional, conforme é possível observar, na figura seguinte.

Fig. 2: Os "nós" de ligação na região de Picos/PI.

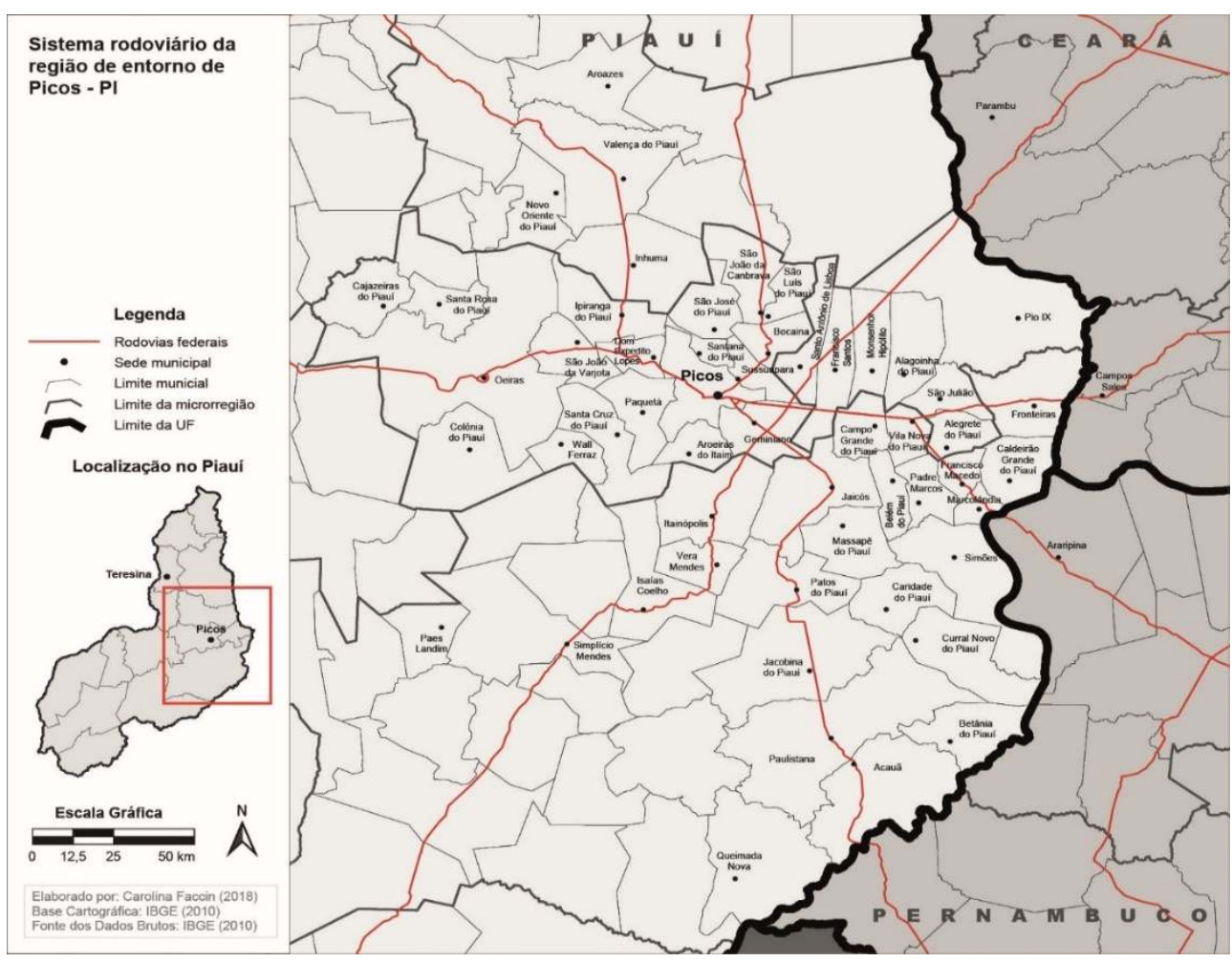

Fonte: IBGE (2010).

Como se vê, a cidade de Picos está interconectada por rodovias federais, estaduais e uma multiplicidade de caminhos que conectam o rural com o urbano. Tal condição, revela uma forte capacidade de integração e complementariedade, entre as partes municipais, em interações.

A funcionalidade assumida, no interior de sua região, lhe agrega uma qualificação extra: uma espécie de "caixa de ressonância", dos processos socioespaciais que de forma dinâmica e constante se desenvolvem. Esta capacidade ganha visibilidade, quando olhamos não apenas para Picos, mas particularmente, o conjunto de outros municípios que compõe seu quadro regional de referência.

Estes fatos, nos dão elementos e condições convincentes, a partir de Picos, para a compreensão da mesma, enquanto uma cidade de comando regional. Colabora para esta essa tomada, a necessidade de não interpretar aquela cidade sertaneja piauiense e suas qualificações, à luz do rico e não consensual debate conceitual, em que são apresentadas 
muitas variações da terminologia, sobre as cidades médias, a saber: intermedias/ intermediarias e ou de porte médio.

41 Com isso, não é pretendido encerrar e ou negar o valor do debate em tela, mas sim, oportunizar o alargamento do mesmo, por meio de outras perspectivas e critérios, pois, tão importante como "definir preteritamente a escala de abordagem da investigação é a não definição do centro urbano como cidade média antes da realização da pesquisa, uma vez que a cidade deve ser primeiramente analisada para depois ser definida como média [...]" (OLIVEIRA \& SOARES, 2014, p. 119).

42 Nestes termos, a persistência das nomenclaturas que ainda colaboram para a ideia quantitativa, do que são e representam estas cidades, instiga a refletir que o termo médio e seus correlatos, dada as fortes transformações internas, bem como suas capacidades funcionais na região onde estão inseridas, não conseguem mais dar conta do que são e representam as mesmas, seja na escala regional ou nacional.

43 É nesse contexto que, o ideal de Cidades de Comando Regional, se referenda a toda e quaisquer cidades, dentro de seu contexto regional de localização, detentoras de dinâmicas de transformações acumuladas. Contam ainda, uma forte reestruturação, reorganização e novas ocupações de patamares na rede urbana brasileira, fatos que ampliam o convencimento de que o termo cidade média e seus correlatos fragilmente ainda assume uma função explicativa e condições para reflexão.

Nestes termos, as Cidades de Comando Regional, se referem:

todas e quaisquer cidades, independente de seus tamanhos, mas dotadas de capacidades produtivas, com funcionalidades diversas e inseridas dentro dos diferentes circuitos de investimentos capitais, tomando por base, suas potencialidades regionais e respaldadas, por diferentes interações espaciais, responsáveis para processos de integração e/ou desenvolvimento regional" (LIMA; SILVEIRA, 2018, p. 35).

Tal conceituação explicita os elementos necessários para se pensar as cidades e seu contexto regional, qualificando assim, condições para suas funcionalidades. Dessa forma, é possível falar em Cidades de Comando Regional Gaúchas, Paraenses, Pernambucanas, entre muitas outras, a exemplo respectivamente de Santa Cruz do Sul, Santarém, Petrolina, quando comparadas à Picos, no Piauí, tem em comum, o fato de polarizarem um amplo número de municípios, se apresentando como importantes nós, com fortes capacidades de comando, em suas redes e territórios urbano regionais.

Sobre tais cidades, as dimensões econômicas, produtivas e de investimentos, tem revelado mais do que nunca, os sentidos da forte financeirização em que as mesmas tem sido submetidas. Este fato, é respaldado não mero à caso, na busca de aproveitamento das potencialidades regionais.

Por fim, dois termos que não são valorizados nas discussões sobre as cidades médias e suas variações, ao considerar seus papeis, em seus contextos regionais: a capacidade das cidades de comando promover integração e ou desenvolvimento regional. Picos, nesse entendimento, empiricamente falando, é uma Cidade de Comando Regional Piauiense, como se verá, mais adiante, com fortes condições de integração e menos de desenvolvimento, em sua região. 


\section{Picos/PI: da sua localização à sua caracterização regional}

Para fins de apresentação, Picos/PI, no contexto do território piauiense, está situada no Sudeste do Piauí, nos recortes do semiárido, conforme é observado na figura 3, a seguir. Em termos demográficos, a estimativa populacional do município para o ano de 2018, era de 78.002 habitantes (IBGE, 2018).

Fig. 3: Mapa de localização de Picos/PI.

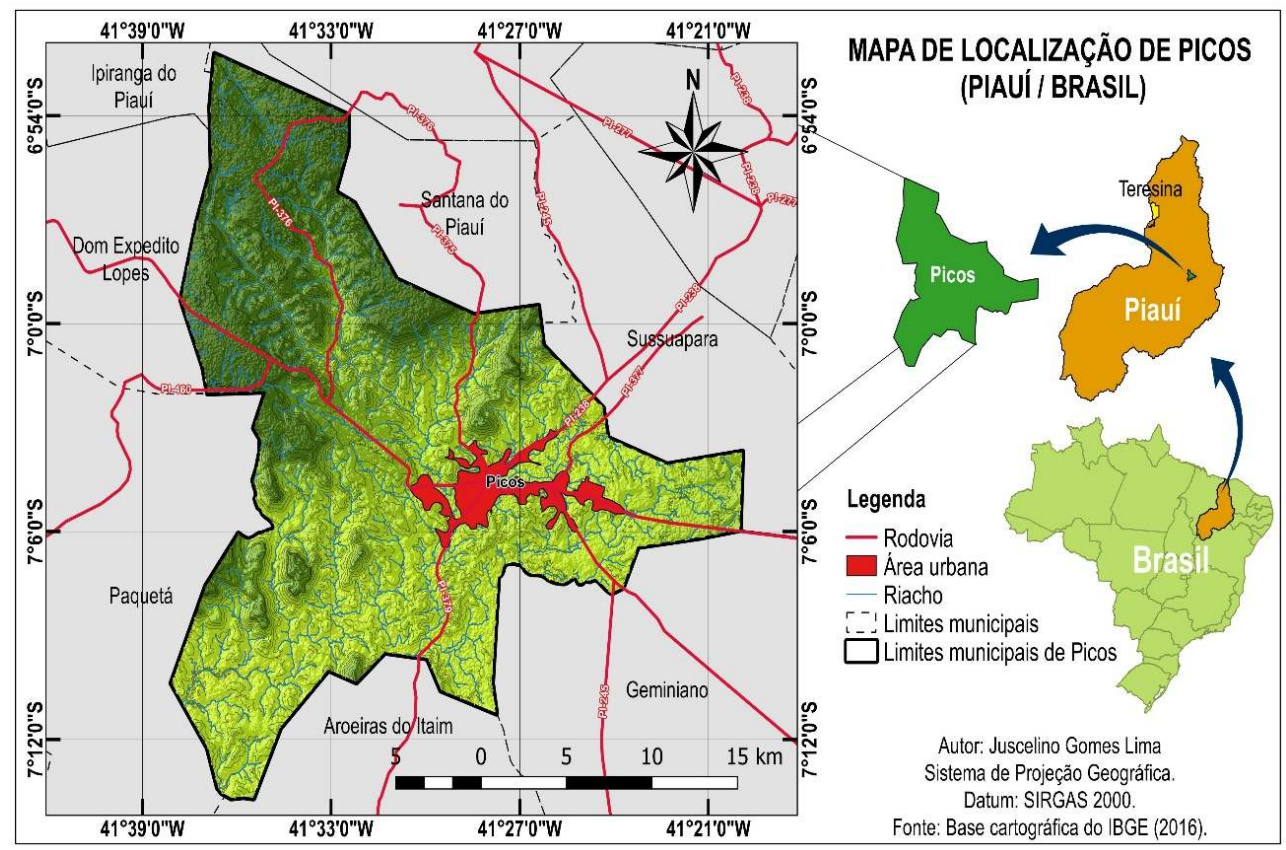

Fonte: IBGE (2016).

Distante 307 km da capital do Piauí, Teresina, a cidade de Picos, tem sua localização em espaço geoambiental sertanejo, assim como também, o conjunto de outros municípios, que por ela são polarizados. Tal localização, rendem-lhes, seja do ponto de vista e conteúdo paisagístico, seja do ponto de vista produtivo, distinção ímpar, quando comparado à capital Teresina.

51 Este último ponto ganha dimensão ao se considerar que, o período das secas anuais (de junho a dezembro, com findar do período concentrado de chuvas), é marca registrada dos sertões. Tal registro, por um lado, é sinônimo de desconforto térmico e agruras sociais graves. Por outro lado, em aspecto positivo, é contribuinte para expressivas produtividades, oriundas dos Arranjos Produtivos Locais (APL's) do Caju e Apícola.

Os processos produtivos, a partir de tais APL's, têm desde o fim dos anos de 1990, animado e reorganizado as novas relações entre o campo e a cidade. Tal condição, entre os anos de 1980 até a primeira metade dos anos de 1990, foi determinada pela produção de alho, às margens do Rio Guaribas. Este, apesar de temporário na fase anual de chuvas concentradas, permite a renovação do espírito produtivo e de esperanças, em dias melhores, do homem sertanejo. 
53 Após o declínio dos ciclos produtivos e econômicos, a partir da dinâmica produtiva do alho, a emergência dos arranjos em questão foi determinante em grande medida, para o posicionamento que Picos assumiu, dentro do quadro regional, conjuntamente com outros municípios, sob sua influência. Caracteriza este conjunto de municípios na região, as múltiplas interações espaciais representadas pelas dinâmicas de mobilidade populacional.

54 É nesse contexto que Picos, em seu recorte regional, tem se apresentando "como uma espécie de "escritório" do setor rural. A presença de vários bancos, instituições de pesquisas, lojas de incrementos e insumos agrícolas reforçam as atividades rurais" (LIMA et al 2017, p. 18)

55 Ainda pautado em sua localização, enquanto ponto de partida de apresentação, é importante mencionar que Picos/PI, apresenta elementos indicativos que influenciam a sua centralidade urbana, seja no contexto interurbano, como também na escala interregional.

56 Um dos primeiros elementos, fala da sua importância, enquanto travessia, entre diferentes fluxos de pessoas e mercadorias, já que é o segundo maior entroncamento rodoviário do Nordeste brasileiro (o maior considerado, é Feira de Santana/BA), atravessado pela BR 230 (rodovia Transamazônica).

57 Outros motivos apontam ainda nessa direção: a concentração de um amplo cabedal, de atividades comerciais e de serviços, abastecendo e atendendo uma grande quantidade de municípios, tanto nos sertões piauiense, como também dos estados do Ceará e Pernambuco, uma vez que, seu raio de influências regionais, se dá sobre 55 municípios, extrapolando assim, as fronteiras do Piauí, conforme se vê, na figura 4 a seguir.

58 É importante lembrar que, tal amostragem, é pautado primeiramente no levantamento dos estudos do REGIC IBGE (2007). Por meio deste, Picos possui um raio de influência regional sobre 34 municípios. Por meio de pesquisas empíricas encabeçada por Lima (2019), foi detectado mais 21 municípios polarizados. 


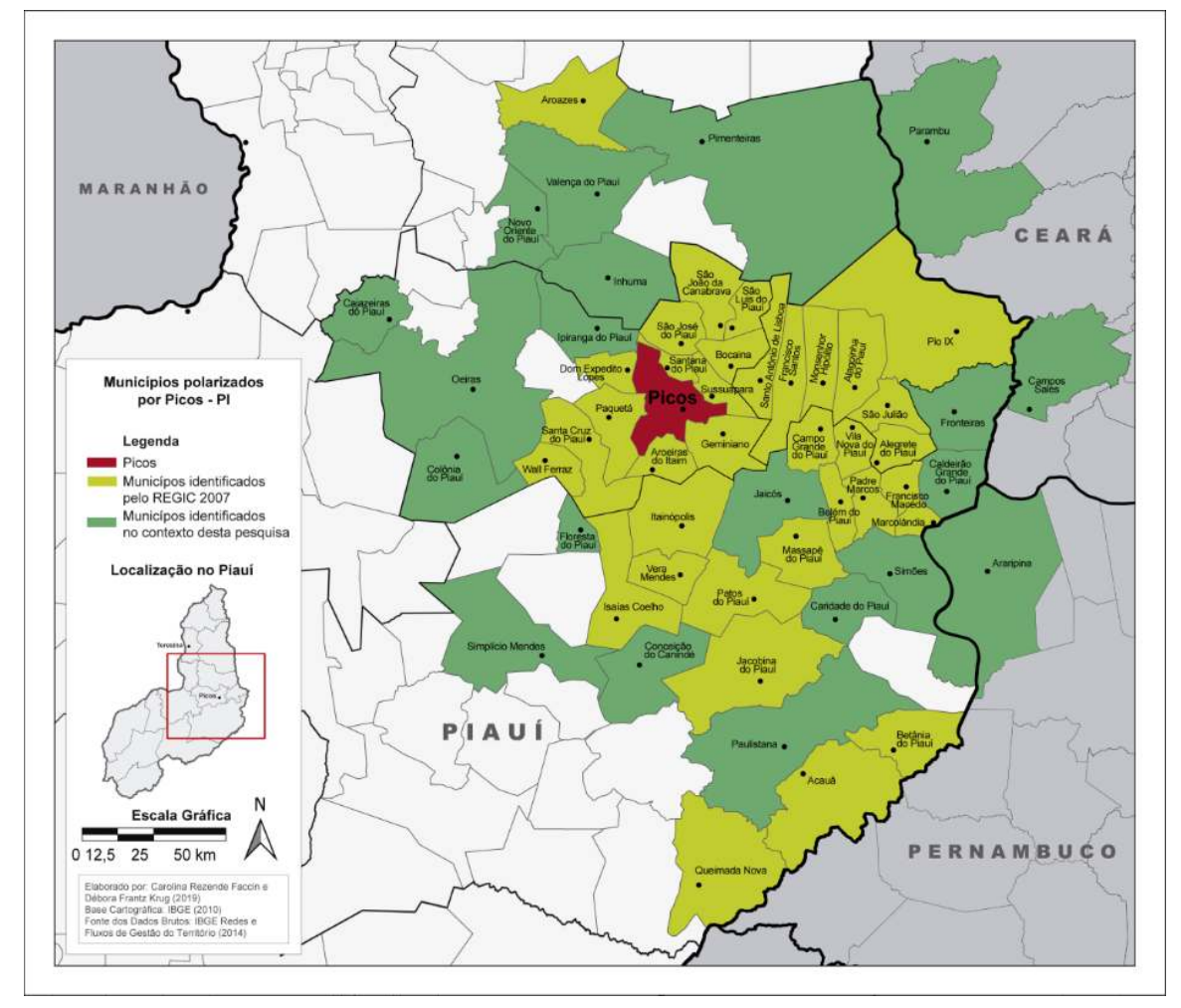

Fonte: IBGE (2010); Lima (2019).

O grande destaque da amostragem, são as cidades que se localizam externamente ao território piauiense. Como já dito, pesa nessa capacidade, de ampla polarização e comando regional, a partir de Picos, os motivos do poder comercial e de serviços ofertados. Associado a isto, sua estratégica localização nos sertões leste do Piauí, enquanto importante entroncamento rodoviário do Nordeste brasileiro.

Além destes fatos, é importante lembrar que todas estas cidades, estão a muitas centenas de quilômetros distantes das capitais de seus respectivos estados. Tal fato, respalda o conjunto de motivos atrativos, para o poder centralizador de Picos e assim, a consolidação de sua capacidade de comando regional.

61 Analisando o alargado poder de polarização, influências e comando regional de Picos, numa perspectiva comparativa, é tomado duas importantes cidades, também localizadas nos sertões nordestinos: Sobral (CE) e Mossoró (RN). Ambas em comum, possuem uma população em mais de 220 mil habitantes. São importantes nós, de sua rede urbano regional, cuja principal marca de suas economias, é a dinâmica de comércios e serviços, além de industrial. Nesse sentido, pelos estudos do REGIC (IBGE, 2007), Sobral (CE), apresenta, um raio de influência sobre 34 municípios, enquanto Mossoró (RN), contabiliza 35 , no total.

62 Apenas a título de informação, as cidades de Sobral (CE) e Mossoró (RN), gigantes do interior do Nordeste brasileiro, tem capacidades e qualidades, sejam elas econômicas, bem como produtivas, bem superiores à Picos. No entanto, a própria história de Picos $\mathrm{e}$ suas diferentes fases, nos diferentes contextos de formação socioespacial e econômico, colaboraram decisivamente para a determinação de seu papel, funcionalidades, importância e logicamente de comando, no contexto regional dos sertões do Piauí. 


\section{Região sertaneja do Piauí em interatividade: Picos/PI em destaque}

forme já visto, as interações espaciais entre Picos e os municípios de seu contexto regional, em tempo atual, tem sua gênese a partir da reestruturação produtiva, oriunda do campo, com o fim das atividades em torno da cultura do alho, às margens do Rio Guaribas e a emergência dos APL's.

$\mathrm{O}$ conjunto de mudanças, não apenas reorganizou a relação campo x cidade, como também reestruturou um quadro econômico de uma região pobre, cuja dependência dos fatores naturais (períodos de seca x períodos de chuvas), ainda é forte, sobretudo, no que diz respeito à garantia de trabalho e sustento, em inúmeros lares, nos sertões do Piaui.

Junto desta dependência, além da reestruturação não só produtiva, como também econômica, foi possível a emergência e posicionamento de Picos, enquanto uma cidade de referência, na região em apreço. Tal condição, é pautada na concentração de diferentes equipamentos comerciais e de serviços, fato que consagra àquela cidade, a condição de uma "bacia" de empregos.

Estes fatos associados explicam e justificam a dimensão dos fluxos, processados na tessitura das relações interurbanas, entre Picos e os municípios polarizados. A partir da tabela 1 a seguir, é possível o vislumbrar do quadro de mobilidades e transportes, sobre Picos. Tais dinâmicas, de movimentos diários, não ao mero à caso, lhe posicionam como uma importante FUA.

Tabela 1: Picos - mobilidade e transportes no território regional.

Picos - Mobilidade e transportes no território regional

- 130 linhas transportes alternativos:

- 14 empresas intermunicipais;

- 4 empresas intermunicipal/inter-regional;

- Aproximadamente 200 veículos clandestinos:

- Semanalmente recebe uma população 20-40 mil pessoas.

Fonte: Secretaria de Trânsito da Prefeitura de Picos e COOCAVEPI (2017)

Os números ao tempo que impressionam pela grandeza, já que estamos falando de uma cidade que contém menos de 80 mil habitantes, nos mostram que os mesmos, resultam do comando que Picos possui, sobre 55 outras cidades, com até $200 \mathrm{~km}$ de distância.

Obviamente, há outros motivos, além do consumo, que são influenciadores para ciranda de fluxos populacionais, rumo a Picos. Contribuem decisivamente nesse sentido, os deslocamentos em função de trabalho e estudos. A tomada destes dois motivos é capaz de explicar e justificar também, por meio das fortes mobilidades populacionais, as diferentes capacidades geradoras, do fenômeno do policentrismo e a reafirmação de Picos, enquanto uma FUA, conforme se vê, resumidamente, na figura 5 , abaixo 
Fig. 5: Percentual da PEA deslocada rumo à Picos, para estudos e trabalho.

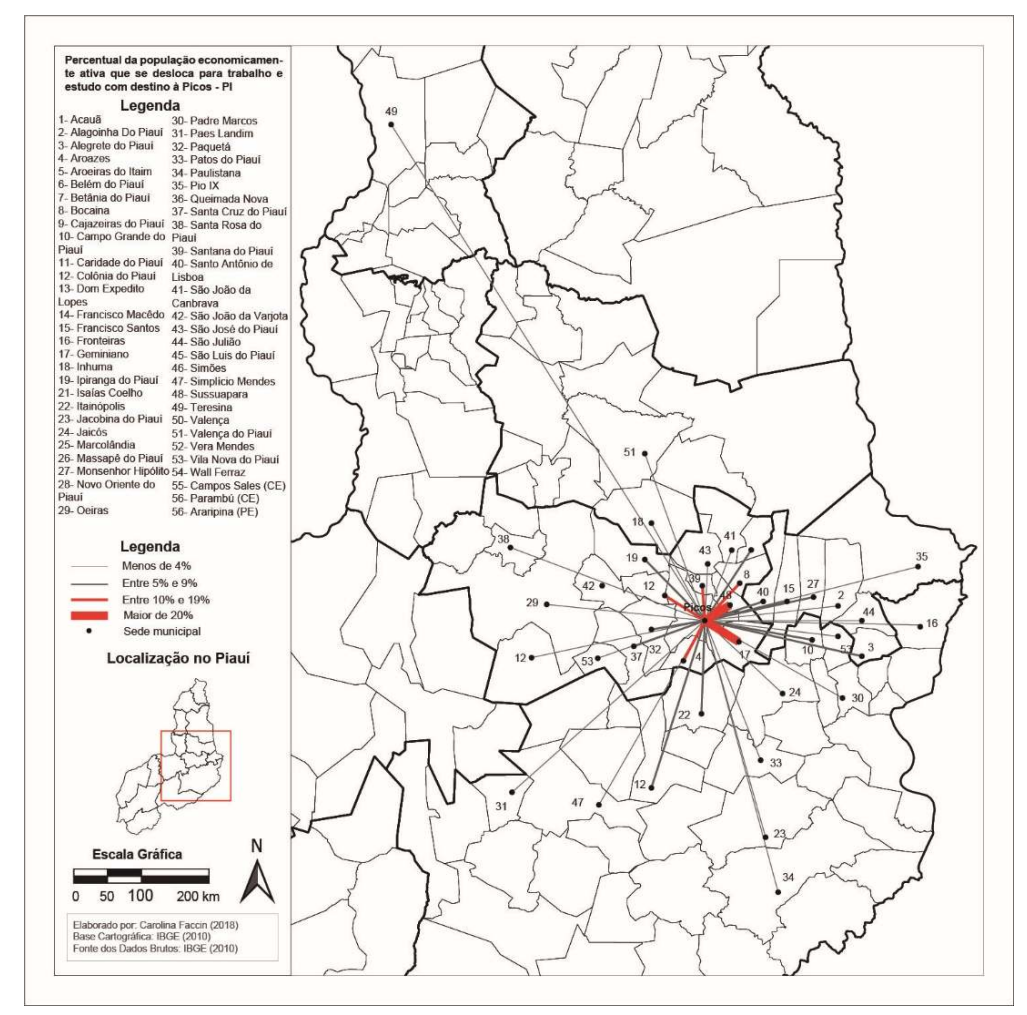

Fonte: IBGE (2010).

Antes de mais, cumpre informar que os municípios em amostragem, segundo dados do IBGE (2010), no que se refere ao fator trabalho, são os que mais contribuem/ofertam, em termos populacionais, com mão de obra, para a cidade de Picos. Nisso, cumpre informar que não são todos os 55 municípios polarizados, mas principalmente, os geograficamente mais próximos à Picos (Bocaina, Geminiano, etc.).

No que se refere ao fator estudos, congrega poder atrativo mais amplo, de modo que, Picos em seu território regional, consegue atrair pessoas interessadas em cursar uma universidade, fora dos quadros, da capital Teresina.

71 Assim sendo, tais fluxos, de natureza quantitativa, caracteriza o percentual de pessoas que se deslocam de um dado município rumo à Picos, considerando a relação da população economicamente ativa do município, em que o fluxo se origina.

Nesse contexto, o IBGE, por meio de seu estudo "Arranjos populacionais e concentrações urbanas do Brasil", considera como valor mínimo, na taxação da PEA deslocada, o percentual de $10 \%$. Entretanto, dada às particularidades do território regional de Picos, é considerado aqueles que apresentam ao menos, $5 \%$ de sua população economicamente ativa, se deslocando para Picos, para trabalho e estudos.

Enquanto análise dos números, algumas ponderações são necessárias. A primeira diz respeito da publicação do estudo, que é 2010, fato, que reforça a existência de outras realidades, que por ventura, podem colocar a importância regional de Picos, mais ampla, a partir dos dados, dada a carência de novas atualizações.

Nesse sentido, a outra ponderação, já agora de fato, com os municípios listados, é a tomada do referencial geográfico de localização dos mesmos, com maior taxa de 
deslocamento para Picos: geograficamente, quanto mais próximos de Picos, maiores são as taxas em destaque. Tal fato, colabora para compreensão do quanto se faz importante, a geração de empregos em Picos, em diferentes setores econômicos, para os pequenos municípios polarizados.

A tabela 2 a seguir, além de mostrar os municípios com proximidade com Picos, revela também os ramos em que as parcelas da PEA, mais se destinam ao trabalho, em Picos. A partir dos mesmos, é compreensível a força de determinados segmentos, para com o dinamismo que se faz, entre as atividades de comércios e serviços, regionalmente demandados e ofertados, naquela cidade sertaneja piauiense.

É importante lembrar que, o conjunto de municípios aí listados, a grande maior parte, tem a "vida econômica", particularmente, a empregatícia, fortemente vinculadas ao setor primário da economia. Isso leva a refletir, a dependência de parcela significativa de suas populações, para o amplo conjunto de oportunidades de trabalho, concentrado em Picos.

Tabela 2: Populações que se destinam a Picos, à trabalho, conforme setores e atividades empregatícia.

\begin{tabular}{|c|c|c|c|c|c|c|c|c|}
\hline \multirow{2}{*}{ Image } & \multicolumn{8}{|c|}{ 10281B38000083A300005EB3CE562407172FEE7C.em } \\
\hline & & res de ati & dades $s$ & gunc & Classes C: & NAE- & & \\
\hline \multirow{11}{*}{ 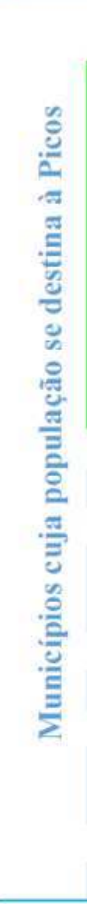 } & 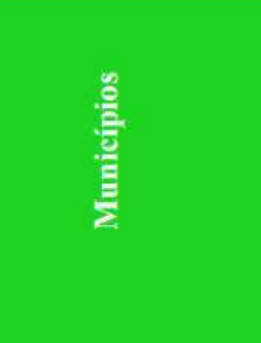 & 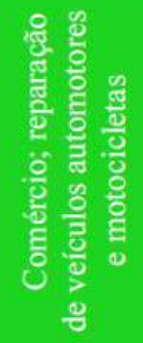 & 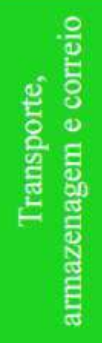 & 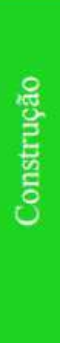 & 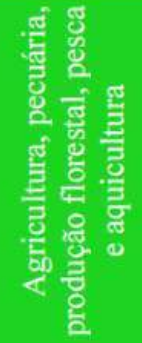 & 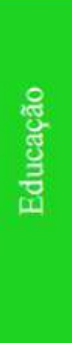 & 퓽 & 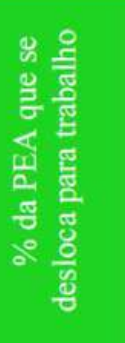 \\
\hline & Alegrete do Piauí & & 18 & & & & 4289 & $1,01 \%$ \\
\hline & Aroeiras do Itaim & 38 & & & & & 2137 & $3,45 \%$ \\
\hline & Bocaina & & & 28 & & & 3812 & $1,61 \%$ \\
\hline & $\begin{array}{l}\text { Dom Expedito } \\
\text { Lopes }\end{array}$ & 46 & & & & & 5612 & $1,77 \%$ \\
\hline & Francisco Santos & & & & & 42 & 7205 & $1,07 \%$ \\
\hline & Geminiano & 107 & & & & & 4546 & $4,92 \%$ \\
\hline & Santana do Piauí & 51 & & & & & 4151 & $2,52 \%$ \\
\hline & $\begin{array}{l}\text { Santo Antônio de } \\
\text { Lisboa }\end{array}$ & 20 & & & & & 5058 & $0,66 \%$ \\
\hline & São Luís do Piauí & 19 & & & & & 2131 & $1,94 \%$ \\
\hline & Sussuapara & 155 & & & & & 5321 & $6,02 \%$ \\
\hline
\end{tabular}

Fonte: IBGE (2010).

No tocante à amostragem da pesquisa, feita pelo IBGE (2010) e, dada as particularidades dos números da PEA, que interessam ao debate nesse momento, convém informar que, optou-se por dar registro, aos setores com maior participação, pois, pela descrição do Instituto, há municípios da lista em questão, que aparece mais de uma vez, mas com participações, em termos de valores, por vezes irrisório.

O setor de comércios que agregam serviços de reparos em veículos automotores e motocicletas foi o grande destaque. Geminiano e Sussuapara, apesar de possuírem de forma total, uma população muito pequena, cede a maior parte de sua PEA, a este setor, em Picos. Com isso, vale destacar que na amostragem ofertada, nessa análise, prevalece o 
enfoque do poder dos municípios geograficamente, os mais próximos possíveis, enquanto importante abastecedores de mão de obra à Picos.

Faz complementação, na visualização do poder centralizador, a partir de Picos, em seu contexto regional, outro fator, para fortes movimentações pendulares, o fator estudos. Nessa oportunidade, lembramos as inúmeras consequências, nos territórios, a partir do fortalecimento das políticas públicas, com vistas à expansão e interiorização do ensino.

A expansão regional de muitas unidades educacionais, de ensino técnico e superior no Brasil, é fruto de uma época em grandes investimentos, de políticas públicas estudantis, pesquisa e ensino, fortemente centradas no governo do ex - presidente Luís Inácio Lula da Silva (2003-2011). o foco ficou concentrado nos níveis superiores da educação nacional, fato que, indiscutivelmente, posicionou reflexos acerca das "novas lógicas de funcionamento do conjunto dos lugares do território nacional" (FREIRE; HOLANDA, 2016, p. 2).

81 Convém lembrar que, pelo Censo Escolar (2018), do Instituto Nacional de Estudos e Pesquisas Educacionais Anísio Teixeira - INEP - Picos abriga 99 unidades escolares, ofertantes do ensino básico, distribuídas entre rede municipal, estadual e federal. Entre estas, sobre as duas primeiras redes, prevalecem o maior quantitativo, contra a presença, apenas de uma unidade do Instituto Federal de Ciência e Tecnologia.

No que se refere as Instituições de Ensino Superior, além da presença da Universidade Federal, Estadual e o próprio Instituto Federal, que oferta cursos superiores, há uma diversidade de faculdades particulares, atuantes em Picos. Fazem soma aí, diversas instituições particulares, com cursos técnicos e idiomas, que impulsionam e motivam, os fluxos populacionais, que buscam oportunidades de qualificação.

Por meio destas descrições, fica claro a lógica de funcionamento e dinâmicas dos fluxos populacionais, a partir dos fatores emprego e estudos sobre Picos. No que se refere, à disponibilidade das vagas de trabalho, a soma dos números, se faz positiva, por conta da presença de novas empresas abertas, na cidade, conforme se vê, na tabela 3, a seguir.

Tabela 3: Quantitativo de empresas abertas em Picos/PI.

\begin{tabular}{|ccc}
\hline \multicolumn{2}{c}{ Quantitativo de empresas abertas em Picos/PI (2011-2018) } \\
\hline Ano & Quantidade & Variação \\
\hline 2011 & 521 & --- \\
2012 & 418 & $-24,5 \%$ \\
2013 & 651 & $+36 \%$ \\
2014 & 519 & $-25,5 \%$ \\
2015 & 328 & $-36,5 \%$ \\
2016 & 497 & $+47 \%$ \\
2017 & 664 & $+34 \%$ \\
2018 & 541 & $-18,5 \%$ \\
\hline
\end{tabular}

Fonte: Secretaria de Finanças de Picos, 2018.

Pelos dados, apesar da oscilação entre os anos amostrais, com ao menos 3 anos, com resultados negativos, mas seguidamente por saldos positivos, a quantidade de empresas abertas só reforça a tamanha força de Picos, no cenário regional, na qual se localiza. Estes fatos atestam assim, a importância de Picos, no contexto dos diferentes investimentos e geração, portanto, de postos de trabalho. 

de saciar múltiplas necessidades materiais, por parte de diferentes conjuntos populacionais interessados, mas, sobretudo, em reconhecer os motivos que lhe enquadrem como tal. também de mantenedor de relações. Estas se dão entre os diferentes municípios, do conjunto polarizados/comandados por Picos, cuja principal marca se faz manisfestada pelas interdependências constituidas, bem como, pelas interações espaciais, já caracterizadas. 


\section{BIBLIOGRAFIA}

ANDRADE, Alexandre Carvalho de. As cidades médias e suas inserções nos espaços regionais: o contexto do Sul de Minas. Revista Territorium Terram, v. 5, p. 64-79, 2015.

ANTIKAINEN, Janne. The concept of Functional Urban Area: findings of the ESPON Project 1.1.1. Informationen zur Raumentwicklung. v. 7, p. 447-452, 2005.

BRASIL. MEC. Instituto Nacional de Estudos e Pesquisas Educacionais Anísio Teixeira (INEP). Censo da Educação: Sinopse Estatística - 2018. < http://inep.gov.br/censo-escolar >. Acessado em 17 de março de 2019.

DÜHR, Stefanie. Potentials for Polycentric Development in Europe: the ESPON 1.1.1 Project Report. Planning Practice \& Research, Abingdon: Carfax Publishing, v.20, n.2, , p. 235-239, 2005.

ESPON. Potentials for polycentric development in Europe - Final Report 1.1.1.European Spatial Planning Observation Network, Comissão Europeia, Bruxelas, 2005. <https://www.espon.eu/ sites/default/files/attachments/fr-1.1.1_revised-full_0.pdf> . Acessado em 22 de fevereiro de 2019.

The Functional Urban Areas Database - ESPON 2013, Database, 2011. < http://

database.espon.eu/db2/jsf/DicoSpatialUnits/DicoSpatialUnits_onehtml/index.html> . Acessado em 22 de fevereiro de 2019.

FERRÃO, João. Regiões Funcionais, Relações urbano-rurais e Política de Coesão Pós-2013. Lisboa: ICS. Relatório Final. Julho, 2012. .<http://www.qren.pt/np4/np4/?

newsId=1334\&fileName=regioes_funcionais.pdf.>. Acessado em 15 de janeiro de 2019.

FREIRE, Heronilson P.; HOLANDA, Virginia. Célia C. A expansão do ensino superior nas cidades médias do nordeste brasileiro. In: XVIII Encontro Nacional de Geógrafos, 2016, São Luís. Anais do XVIII Encontro Nacional de Geógrafos, 2016.

GREEN, Nick. Functional Polycentricity: a Formal Definition in Terms of Social Network Analysis. Urban Studies, Essex: Longman Group, v.44, n.11, p. 2077-2103, 2007.

IBGE. Regiões de Influencias das Cidades. Rio de Janeiro: FIBGE. 2007.

Centros de Gestão do Território. Rio de Janeiro: FIBGE. 2014.< https://

biblioteca.ibge.gov.br/visualizacao/livros/liv86286.pdf.>. Acessado em 15 de janeiro de 2019.

Estimativas populacionais para os municípios e para as Unidades da Federação brasileiros. Rio de Janeiro: FIBE, 2018. <https://www.ibge.gov.br/estatisticas/sociais/populacao/9109projecao-dapopulacao.html?=\&t=downloads. .> Acessado em 15 de janeiro de 2019.

KARLSSON, Charlie., OLSSON Michael. The indentification of funcional regions: theory, methods, and applications. Ann Reg Sci, no 40, p.1-18, 2006.

LIMA, Juscelino G. Território atrasado com estratégias de desenvolvimento regional recentes: evolução do planejamento territorial no estado do Piauí. In: COSTA, Renato. S. S. (Org.). Cenários geográficos e suas complexidades. Teresina: IFPI, 215 p, 2017.

LIMA, Juscelino G.; SILVEIRA, Rogério. L. L da. Cidades Médias Brasileiras a Partir de um Novo Olhar Denominal e Conceitual: Cidades de Comando Regional. Desenvolvimento em Questão. n. 42, p. 8-41, 2018. 
NUNES, Goretti; MOTA, Isabel; CAMPOS, Pedro. Policentrismo Funcional: uma Avaliação dos Municípios Portugueses. Revista Portuguesa de Estudos Regionais, n.ํ2 29, p. 27-38, 2012.

OLIVEIRA, Antônio T. R. de. Dos movimentos de população à pendularidade: uma revisão do fenômeno migratório no brasil. In: XV Encontro Nacional de Estudos Populacionais - desafios e oportunidades do crescimento zero. ABEP: Caxambu, 2006.

OLIVEIRA, Hélio C. M. de; SOARES, Beatriz. R. Cidade média: apontamentos metodológicos e tipologia. Revista Caminhos de Geografia, Uberlândia, v. 15, n. 52, p. 119-133, 2014.

PESSOA, Renata P. P. Urban Synergy looking for Dealing with Polycentric Development: The Case of the Metropolitan Agglomeration of Fortaleza. Dissertacao de Mestrado. Programa de Pós Graduacao em Arquitetura e Urbanismo. Universidade Técnica de Delft, Delft, 151 p, 2010.

SILVEIRA, Rogério. L. L.; BRANDT, Grazielle. B., FACCIN, Carolina. R. , SILVEIRA, Leonardo L., KUMMER, Débora C. . Policentrismo, Áreas Urbanas Funcionais (FUAs) e Dinâmica Territorial: Um estudo exploratório desde a região do Vale do Rio Pardo - RS - Brasil. Revista Redes, Santa Cruz do Sul, v. 22, p. 184-217, 2017.

\section{RESUMOS}

O presente artigo analisa a cidade de Picos/PI, enquanto uma Área Urbana Funcional (FUA), bem como, a constituição de um forte policentrismo, cujos aspectos tomados, são os da morfologia e as relações entre àreas urbanas, decorrentes das diferentes interações e dinâmicas espaciais, em seu território regional. Dois caminhos metodológicos norteiam a construção da pesquisa: o primeiro, de base teórica, entre diferentes pensadores, na literatura urbana e regional. o segundo, de natureza quantitativa, por meio de diferentes dados, com destaque, para os estudos do IBGE: Gestão do Território - Fluxos e Redes (2014) e REGIC (2007). As múltiplas interações espaciais, representadas, pelos diversificados fluxos, têm contribuído para fortes dinâmicas nos sertões do Piauí. A capacidade de comando regional de Picos tem reafirmado sua condição de uma importante Área Urbana Funcional (FUA), em seu contexto regional. Os aspectos policêntricos apontados são animados e resultam dessa premissa.

Le présent texte analyse la ville de Picos/PI, en tant qu'Espace Urbain Fonctionnel (EUF), ainsi que la constitution d'un polycentrisme fort, dont les aspects sont tirés de la morphologie et des relations entre zones urbaines, résultant des différentes interactions et dynamiques spatiales, dans son territoire régional. Deux voies méthodologiques guident la construction de la recherche: la première, théoriquement fondée, entre différents penseurs, dans la littérature urbaine et régionale. La seconde, de nature quantitative, au moyen de différentes données, en particulier, pour les études IBGE: Gestion des territoires - Flux et réseaux (2014) et REGIC (2007). Les multiples interactions spatiales, représentées par les flux diversifiés, ont contribué à une forte dynamique dans les sertões du Piauí. La capacité de commandement régional de Picos a réaffirmé son statut de Espace Urbain Fonctionnel (EUF) importante dans son contexte régional. Les aspects polycentriques mis en évidence sont animés et résultent de cette prémisse.

El presente texto, analisa la ciudad de Picos/PI, mientras una Área Urbana Funcional (FUA), bien como, la constitución de un fuerte policentrismo, cuyo aspectos tomados, son los de la morfología y las relaciones entre áreas urbanas, debido las distintas interacciones y dinámicas espaciales en su territorio regional. Dos caminos metodológicos guian la construción de la pesquisa: el primero, de base teórica, entre distintos pensadores en la literatura urbana y regional. El segundo, de naturaleza cuantitativa, por medio de datos distintos, con destaque para los estudios de IBGE: Gestão do Território - Fluxos e Redes (2014) e REGIC (2007). Las múltiplas interacciones espaciales 
representadas por los diversificados flujos han contribuído para fuertes dinámicas en los sertones de Piauí. La capacidad de comando regional de Picos ha reafirmado su condicción de una importante Área Urbana Funcional (FUA) en su contexto regional. Los aspectos policéntricos apontados son dinámicos y resultan de esa premisa

This study analyzes the city of Picos/PI, while a Functional Urban Area (FUA), as well as the constitution of a strong policentrism, in which the regarded aspects are the morphology and the relationship among the urban areas, due to different interactions and spatial dynamics in its regional territory. Two methodological paths guide the doing of this research: the first one, from theoretical basis among different thinkers in the urban and regional literature. The second one, from quantitative nature, considering different data, with special focus on the IBGE studies: Gestão de Território - Fluxos e Redes (2014) and REGIC (2007). The multiple spatial interactions, represented by diversified flows have contributed for solid dynamics in the Piauí outbacks. Picos capacity of regional command has reassured its condition as an important Functional Urban Area (FUA) in its regional context. The policentric aspects indicated are dynamic and derive from its assumption

\section{ÍNDICE}

Mots-clés: Espace Urbain Fonctionnel. Polycentrisme. Dynamique spatiale. Picos.

Keywords: Functional Urban Area (FUA). Policentrism. Spatial Dynamics. Picos

Palabras claves: Área Urbana Funcional. Policentrismo. Dinámicas espaciales. Picos.

Palavras-chave: Área Urbana Funcional. Policentrismo. Dinâmicas espaciais. Picos.

\section{AUTOR}

\section{JUSCELINO GOMES LIMA}

Universidade de Santa Cruz do Sul - UNISC. Doutor em Desenvolvimento Regional. geocelino@hotmail.com 